\title{
Reflexiones sobre economía y humanismo como modelo para la formación integral
}

\author{
Jacques Carbou ${ }^{1}$
}

Recibido: 10 de octubre de 2015

Aprobado: 14 de noviembre de 2015

\begin{abstract}
Carbou, J. (2015). Reflexiones sobre economía y humanismo como modelo para la formación integral. Activos, 25, 25-30.
\end{abstract}

\section{Clasificación JEL: A12, A13.}

\section{Resumen}

Este corto artículo de reflexión es una invitación a los economistas y a otros estudiosos de las disciplinas económicas para no olvidar la integralidad de esta con otras ciencias humanas, y aún más importante, la capacidad que este enfoque tiene para aportar a la formación integral de los estudiantes que se aproximan al conocimiento económico.

Resalta la importancia de este tipo de enfoques en la formación humanista promovida por la Universidad Santo Tomás, proponiéndola como un ejemplo a seguir por otras academias.

\section{Palabras clave}

Economía, humanismo, educación, formación integral.

1 Doctor en Ciencias Políticas de la Universidad de Paris 3 - Sorbonne Nouvelle. Economista, docente Universidad Santo Tomás. Correo: jacquescarbou@ usantotomas.edu.co 
Carbou, J. (2015). Reflections on economy and humanism as model for holistic education. Activos, 25, 25-30.

\section{Summary}

This short article of reflection is an invitation for economists and researchers in Economics to maintain an approach open to a comprehensive influence from other human sciences and more importantly, to recognize the advantages of this approach to contribute to the holistic education of students who are interested in economic knowledge.

The importance of this kind of approach stands out in the humanistic education promoted by Universidad Santo Tomás and it is proposed as an example for other schools.

\section{Keywords}

Economy, humanism, education, holistic education.

Carbou, J. (2015). Réflexions sur l'économie comme modelé pour la formation intégrale. Activos, 25, 25-30.

\section{Résumé}

Ce court article de réflexion est une invitation aux économistes, et chercheurs d'autres disciplines proches de léconomie, à ne pas oublier la perspective intégrale de la science économique qu'elle partage avec les autres sciences humaines, et, plus important encore, pour contribuer à la formation des étudiants en science économique.

Ce type de formation humaniste promu par l'université Santo Tomas est proposé comme exemple à suivre par d'autres universités."

\section{Mots clés}

Économie, humanisme, éducation, formation intégrale 


\section{Introducción}

La economía es considerada como una actividad humana sometida a ciertas leyes de acuerdo con las cuales tiene lugar la producción de bienes, su distribución y su consumo; una actividad humana destinada a la producción de ciertos valores de utilidad.

La palabra "economía" etimológicamente proviene del griego Oikonomia de oikos (= casa) y nomos (= ley, norma, administración). En la antigüedad, la economía representaba la administración de la casa y el hogar, las cuentas hogareñas. Aristóteles (en dos obras: Política, libro I. 8-10 y Ética a Nicómaco, V. 5) estudió los precios, la naturaleza del lucro y del interés, la naturaleza de la moneda y del dinero; defendió la propiedad privada porque proporciona una productividad mayor.

Además Aristóteles distingue la economía de la crematística (o adquisición de bienes, de cosas) con un enfoque ético sobre el tema de la riqueza. Pero la economía de la antigüedad no tiene nada que ver con el complejo mundo económico que conocemos. En los tiempos modernos, a finales del siglo XVIII, cuando nace la economía como disciplina o campo de investigación, no se puede olvidar que Adam Smith (1723-1790), antes de escribir Una investigación sobre la naturaleza y causas de la riqueza de las naciones (1776) es el autor de La teoría de los sentimientos morales (1759) y titular de la cátedra de Filosofía Moral de la Universidad de Glasgow, Escocia. Las intuiciones de Adam Smith sobre las elecciones individuales y el equilibrio del mercado abrían un nuevo campo de investigaciones prometedor.

Como escribe Orlando Martínez Montoya (2003): "la ciencia económica se juzga en cuanto sirve el interés del hombre, a la realización del progreso como sistematización de esfuerzos humanos para alcanzar el éxito" (p. 20).

Cuando Martínez (2003) pregunta si existe una ética en el pensamiento económico, añade: 
La acción humana está condicionada por actos de intercambio donde queda implícito que su sujeción a determinadas reglas conlleva el logro de propósitos éticos fundamentales: libertad, progreso, consideraciones sobre la dimensión de la riqueza y sobre el mismo actuar entre individuos (p. 22).

Ahora que hemos visto que existen relaciones entre ética y economía, veamos el tema del humanismo.

La palabra humanismo aparece por primera vez en la primera mitad del siglo XIX. En 1784 se usó el vocablo humanístico; el término humanista fue usado en italiano ya en 1538. Entonces, el término utilizado ya desde el siglo XVI en Italia, fue acuñado por el erudito alemán F.J. Niethammar (en 1808) para referirse a los que se consagraban a los studia humanitatis es decir las lenguas y autores clásicos (latinos y griegos), las artes liberales en sus diversas manifestaciones culturales.

El primer humanismo ha sido, sin duda, el de Roma. Los ulteriores -el del Renacimiento y el del Neoclasicismo- se han limitado a seguirle, sin otra diferencia que lo de poner junto a lo griego lo latino como arquetipo de humanitas: hombre, educación y cultura.

Podemos así definir cuatro sentidos del humanismo:

1. La tendencia a destacar la importancia del estudio de las lenguas y de los autores clásicos, griegos y latinos.

2. El estudio de las "humanidades", estudio "liberal" y no "profesional" que se consagraba a las artes liberales: gramática, retorica, poesía, historia y filosofía moral.

3. El movimiento surgido en Italia hacia fines del siglo XIV y prontamente extendido a otros países en los siglos XV y XVI. Según la concepción del erudito profesor suizo Jacob Burkhardt, a finales del XIX, este movimiento se traduce por "el descubrimiento del hombre como hombre - o como individuo".

4. En la época actual, desde el siglo XX, se pone de relieve algún "ideal humano". Hay un humanismo cristiano (humanismo integral o humanismo de la Encar- 
nación, de Jacques Maritain), un humanismo socialista, un humanismo liberal, un humanismo de influencia científica, un humanismo existencialista y un humanismo marxista. Contra el "humanismo liberal y burgués", arremetieron los estructuralistas y la Escuela de Frankfurt. En la segunda mitad del siglo XX se desarrollaron tendencias anti-humanistas.

El humanismo clásico reconoce la dignidad de la persona humana, la autonomía de la razón humana, la libertad como valor de la persona humana, la tolerancia, la igualación de los derechos fundamentales para todos los hombres sin discriminaciones de raza, sexo, nacionalidad. Pero algunas tendencias humanistas van hasta la autosuficiencia del hombre, basada en un evolucionismo radical.

Un humanismo "absoluto", desviación del humanismo, afirma la soberanía del hombre frente a Dios o a la Naturaleza y coincide con el materialismo. A partir de la idea que el hombre se apropia de la naturaleza por el trabajo, Carlos Marx piensa que la historia universal corresponde al advenimiento del hombre por el trabajo humano. Pero, pregunta el filósofo francés Rémi Brague, ¿cómo el trabajo puede humanizar el que lo hace si ya es un ser humano?

En la concepción atea o marxista del humanismo, el hombre como dueño de la naturaleza se pone como "ser supremo" en competencia con Dios. En los proyectos de una reconstrucción del ser humano, la religión de la humanidad -como en el "positivismo" de Auguste Comte- quiere reemplazar las religiones tradicionales. Estos proyectos, de Comte, de Marx, fracasaron.

Regresamos a la dimensión económica para observar, como lo indica Montoya (2003):

Que el mundo moderno ha olvidado al hombre para centrarse en la noción de lo razonable, que privilegia el intento descarado de oponer la actividad económica abstracta, el homo economicus, a valores morales igualmente abstractos, en lugar de situarse en la relación que contrapone al hombre con su entorno social (p. 21). 
La asignatura de Economía y Humanismo hace parte de la formación integral propiciada por la Universidad Santo Tomás, que no se enmarca solo en la afirmación de un humanismo en la perspectiva de promover la excelencia académica, sino además la dimensión ética que cada profesión orienta a la formación de los futuros profesionales como auténticos lideres con conciencia de sus responsabilidades con la sociedad a la que pertenecen, para responder de una manera ética, creativa y crítica en las exigencias de la vida. La profesión contable tiene también su código de ética y sus principios (Montoya, 2003): integridad, objetividad, independencia, responsabilidad, confidencialidad, observación de las disposiciones normativas, competencia y actualización profesional, difusión y colaboración, respeto entre colegas y conducta ética.

\section{Referencias}

Martínez, O. (2003). Ensayos de filosofía y economía. Bogotá: Universidad Santo Tomás, Facultad de Economía.

Montoya, J. D. (2003). Noción de ética profesional y responsabilidad social del contador público. Activos, 16(17), 51-68. 